\title{
Quantitative analysis of business process reengineering deployment in health information technology
}

\section{T. Ray Ruffin}

School of Advanced Studies, University of Phoenix, Phoenix, AZ, USA
Correspondence: T. Ray Ruffin School of Advanced Studies, University of Phoenix, 1625 W. Fountainhead Pkwy, Tempe, Phoenix, AZ 85282-237I, USA Email trruffin@email.phoenix.edu
This article was published in the following Dove Press journal:

Advanced Health Care Technologies

21 November 2016

Number of times this article has been viewed
Abstract: In the arena of health information technology (HIT), utilization efforts are sometimes met with ineffective processes. Medical records documentation is one such area in which these inefficiencies present their selves across the broad scope of health care organizations. Multiple chronic conditions require that clinicians be able to access computerized medical records of other physicians about their patients. These systems do not interact, leaving many clinicians unable to communicate easily and efficiently with their colleagues. Ineffective care coordination causes poor care, and HIT has the ability to improve quality. This study examined the use of business process reengineering (BPR) deployment in the implementation of HIT within health organizations. The purpose of the study was to test the theory of Classical Diffusion of Innovation. The finding revealed that HIT was not being implemented as rapidly as predicted and BPR deployment in the implementation of HIT was inconclusive. However, due to regulations and mandates, HIT implementation has risen. Additional research revealed that the use of BPR is functioning in the analyzation of processes and outcomes of HIT implementation.

Keywords: Classical Diffusion of Innovation, computerized physician order entry, electronic health records, health care organizations, health information exchange

\section{Introduction}

Biotechnology Council-predicted administrative costs calculated to roughly a fourth of each dollar spent for health care in the US. ${ }^{1}$ The Council recommended health information technology (HIT) as a resolution to decreasing administrative cost. ${ }^{1}$ In calculating the cost of medical records, a single physician's cost allocation for administratively processing medical records was US\$163,765 with an overall cost including Medicare and Medicaid of $\$ 30$ billion in financial incentives yearly. ${ }^{1}$ The medical records cost was \$468,000 for Medicare- and Medicaid-contracted providers. Printing costs alone could be reduced by $50 \%$ using electronic health records (EHRs) document generator to process forms. ${ }^{1}$

A hospital budget includes the cost of supplies, improving data, and maintaining processes that frame supply chains. This can take up to a third of the hospital's budget and even more time in updating and training staff to make the necessary accommodations. HIT has the possibility to eliminate massive amounts of paper shuffling, which would save hundreds of billions of dollars. ${ }^{2}$ The Human Health Services quantified this with a savings estimate of $\$ 162$ billion a year if HIT would implement EHR. ${ }^{3}$ The Minnesota Orthopedics Specialist Group eradicated transcription costs, saving over $\$ 125,000$ yearly. ${ }^{1}$ An EHR-based deterrence and supervision of lingering ailments 
could yield a maximum of over $\$ 155$ billion savings annually. Resulting in a reduction of overall health care spending by over $\$ 800$ billion annually, this savings has the potential to reduce health care costs for consumers. ${ }^{4}$

Current designs of EHR systems do not come vaguely close to the capability considered most advantageous. Even though there are numerous vendors venturing into the EHR systems market, there is the problem of limited data standardization across these systems. ${ }^{3}$ For instance, HIT-based clinical reminders for routine childhood vaccines could be programmed to come into view at all health care visits. ${ }^{5}$ This could be a consequence of the systems characteristics that are fine-tuned and correlated for a specific function. As a result, integration with other systems such as computerized physician order entry (CPOE) becomes consistently challenging to undertake. ${ }^{4}$

HIT could provide the tools urgently required to measure, guide, and improve the care of people battling cancer and other critical medical conditions. ${ }^{6}$ An estimated 200,000-400,000 deaths occur per year due to medication errors. These deaths would cost over $\$ 3$ billion, if there were 350,000 medical errors annually. ${ }^{7}$ Mistakes are common, however not intentional. They are instead a direct result of practices or procedures that impact the communication and sharing of defined information. ${ }^{8} \mathrm{CPOE}$ allows health care professionals to quickly and effectively gather the data that is crucial as well as to avoid common and clerical mistakes. CPOE enables the users to increase knowledge that eliminates the chances of errors based on human memory and allows user to effectually deal with concerns immediately affecting patients. ${ }^{7}$ Implementing CPOE with clinical decision support is progressively more encouraged as a solution to medical error reduction and need for enhancement in quality of care. ${ }^{9}$

\section{Technology}

Historically, there have been some negative conations to technology-centered approaches to automation, which has led to the development of human-centered automation. ${ }^{10}$ Two proposed approaches dispute the common views regarding human automation task responsibility in multiple versatile structures. ${ }^{10}$ These approaches systemize the transfer of ideals and concepts to people and automation in areas of a more collaborative group approach. The first approach seeks to pass control back and forth between the human and the automation. ${ }^{10}$ The second keeps both the human and automation involved in systems operations. This allows the assigning of systematic functions to the human, computer, or both. ${ }^{10}$
Spawning the levels of automation, the level of task preparation, routine interaction maintained between a human operator and a computer in controlling a complex system can be a product of these approaches. This enhances systems as they are being introduced to the organization. Pioneers in these particular areas of research found that certain technology adoption models that work well in business environments may not have the same effects, results, or complications that could arise in the health care field. The hesitations of health care specialists, such as physicians, to accept the concept of information technology (IT) for clinical purposes were evident despite the advantages of economic and qualityof-care benefits. ${ }^{8}$ Defined clinical benefits were adequately maintained patient records, no misplaced charts, notice of prescription medicine interactions, access to the most current educational information, printed prescriptions, and improved patient communication options. ${ }^{8}$

Decisions of health care organizations (HCOs) to adopt new technologies were often a reaction to institutional changes in markets or regulatory pressures in the organizational environment. ${ }^{11}$ Barley and Tolbert conjectured that institutional changes were enacted at the microanalytic level. ${ }^{12}$ Theorists have viewed institutions primarily as stabilizing and inhibiting social structure change, but institutions do change. In doing so, they create forces for and against change. ${ }^{13}$ Accounting for institutional change and stability is one theoretic approach to investigate the outcomes of ITrelated organizational change. ${ }^{14}$ Many authors, for example, Feyereisen, suggested that the US health care industry experienced a period of hyper-turbulence in the later 20th century. ${ }^{15}$ HIT has been promoted as an important way to address quality, cost, and regulatory pressures; however, hospitals continue to experience difficulty with HIT acceptance, and adoption rates remain fairly low. ${ }^{16}$

HIT exists to support all stages of computer literacy as well as to provide a continuous replication function that allows physicians to continue to work in real time, in the event of error or lost connections throughout the network. ${ }^{1}$ The key factors in the investments and collaborations need to be analyzed and addressed to successfully transition health organizations into utilization of an operational efficient HIT. This transition should start with a trusted source for coordinated and consistent product information that can be easily accessed by those in the HCOs and its suppliers. ${ }^{8}$

There has to be the realistic viewing that managing IT costs is not just about hardware and software. The costs associated with IT implementation often result in the hesitations and apprehension of HCOs. There has to be an understanding 
of the logistics involved in building, deploying, and managing assets. In a separate report, Gartner identified four specific levels within an organization at which IT investments can help businesses optimize business costs. According to an article by Cognizant, there are four specific levels within an organization at which IT investments can help the businesses optimize business costs; these include the following:

1. Requirement degrees

2. Technical risk

3 . Investment required

4. Impact on customers ${ }^{11}$

IT has a rapid growth in new business opportunities that call for constant change and expensive scaling. ${ }^{11}$ Technology innovation has been progressing to new paradigms outside the traditional systems. Additional elements have entered the industry to help create, drive, and manage business processes around the length of stay. ${ }^{11}$ This includes customer relationship management (CRM) technologies for processing productivity. CRM provided practice for sales managers considering reorganization of their teams. ${ }^{11}$ These fairly new CRM tools were substituted as technological advancements redefine the way HCOs do business. ${ }^{11}$

Today, business process automation is commonplace, and seldom distinguishes high-performance organizations from others. To compete effectively, organizations must look beyond improving operating efficiency to improving their processes for managing performance. ${ }^{11}$ High-performance companies compete on their ability to identify up-and-coming threats and opportunities and to respond to them swiftly, with well-informed decisions. To make excellent managerial decisions, companies need access to information that encompasses not only company performance but also the broader competitive landscape. ${ }^{11}$

\section{Business process reengineering}

In the early stages, original synopsis regarding business process reengineering (BPR) was geared toward a more reliable and organized method to improve upon performance of organizations. This required organizations to apply processes that would include IT as well as restructuring of outdated procedures and practices. This approach was coined with the terms BPR and business process redesign, both of which are referred to as BPR. ${ }^{17}$ Pioneers of BPR birthed the idea of the "clean sheet" approach (ie, a process should be designed from scratch without considering the existing process in too much detail). In an effort to negate the cost of starting over, some organizations may choose to use existing business process as the starting point. ${ }^{17}$ These efforts are completed jointly by brainstorming to help create alternatives that will be more applicable to current business process to assist the organizations with their starting point.

This can be achieved in workshops or conferences that may include consultants, managers, and other personnel who are deemed important to the process. Once an approach or concept is accepted, then the implementation process begins and is often carried out by experts in fields of change management and IT in the organization. Benefits of HIT investment begin with the procurement process. Acquiring HIT hardware and software potentially can enhance HCOs' ability to provide less cost to the patients as well as to allow for higher quality care. The following are eight suggested steps needed to be successful during procurement process:

1. Understand the need: Determine why new hardware is needed. Weigh the positives and the negatives of the decision. Discuss the benefits (ie, reduced costs, improved patient satisfaction) and the risks (ie, high cost of implementation at the start, errors during initial data integration).

2. Capitalize the project: Plan accordingly for all costs by immediately setting budgets to commit to the project in both the short and long term. This is the time that the user should decide if the procurement process should continue or be terminated.

3. Understand the market: Research what the current standards are in reference to BPR guidelines before the procurement process begins. This information will help narrow the product choices before important procurement work is begun.

4. Structure the right team: Identify departments that will be affected by the new hardware and software and formulate teams that will consist of a change manager and IT specialist who can train staff and assist with the changes.

5. Gather vendor information: In this step, the organizations would request information from different parties in the form of proposals, contractual obligations, and portfolios with comparisons. Requesting demonstrations is also a good means of gathering information about potential vendors.

6. Apply drivers and values: Seek out vendors with values and missions that are in line and compatible with the vision of the organization. Review the organization's budget as well as the vendors and their ability to adapt to future changes, if applicable. 
7. Integrate process and system: Procurement of BPR systems should improve the capabilities of the organization. Automation and integration of data across the board should be improved upon and not just an upgrading of existing processing systems.

8. Negotiate wisely: Use expert assistance due to the rapid pace of technology advances in health care. ${ }^{11}$

The process-oriented health care industry would benefit from the results of successful procurement. BPR focuses on achieving specific performance targets, such as specific profit margins, clinical outcomes, quality improvements, or customer satisfaction. Constant monitoring of the HCOs performance should be a factor in determining if BPR goals are being met. BPR should align with the organization's vision and mission set forth from the start. Managers of these systems should also be monitored to ensure that they are contributing to the success of the organization's efforts. ${ }^{11}$ Management tools and techniques will help organizations hold their managers accountable for achieving targeted results. ${ }^{11}$

A tool for BPR is a blueprint. The business blueprint is based on a concept called event-driven process chaining (EPC). EPC is based on four key elements:

1. Events: When should implementation be initiated?

2. Tasks or functions: What functions should be initiated?

3. Organization: Who should do the implementation?

4. Communications: What information is required to implement correctly? ${ }^{18}$

The development of networks of longitudinal, comprehensive, and interoperable HIT offers opportunities for improving coordination of care and the usefulness of records, increasing competence of health care, and avoiding duplication of services. ${ }^{11}$ In BPR, events are the driving force behind a business process, prompting one or more activities to take place. The EPC provides the interconnections among tasks, data, organizational units, and the logical time sequence involved to define a business process. An event can be described as a process or a cycle. An event is continuous and often depends on a prior or beginning task, followed by an eventual or final task to be performed. As each task is performed and concluded to be successful, a complete picture of the business process can be documented and replicated for future users. It will also allow for lesser chances of errors once a structure is put into place. ${ }^{11}$

\section{Change}

Change is a given and necessary. Driving these changes is the constant demand for upgrades in technology and communication. These are two factors that require the thought processes and creativity of managers to change from old ways of doing things. Managers will continue being judged on their ability to efficiently and effectively manage. ${ }^{11}$ The speed of change has considerably intensified from the time when cavern inhabitants strolled the world up until the "technology convergence" to the ox and horse. The world may not be spinning faster; however, the people are. ${ }^{11} \mathrm{~A}$ neighbor or competitor, technologically speaking, could be on the other side of the world; biotechnology is the science of the future. Business managers now face vibrant and multifaceted operating environments.

Technologies and services, along with the organizations they sustain and provide for, are converging. As organizations and services converge, there is a growing realization that a holistic approach to the services is required. ${ }^{19}$ The patient packaging of what separate services into effective "consumer solutions" will continue for the near future. ${ }^{20}$ However, traditional change management gives emphasis to the significance of strengthening and implanting sought-after changes in structures, processes, systems, target setting, and incentives. To be operative, these instruments are required to take into consideration that people do not always behave genuinely. ${ }^{14}$

An accepted truth in organizations is the unavoidability of change. Another is that few organizations achieve the benefits they should. Changeability addresses the positive question of what makes people and organizations good and the ability to manage for the future. In tentative times, pressure for alteration is greater than ever. ${ }^{11}$ The world has changed dramatically over the last few years. Compounding the undesirable outcome of change is the state of the current economy. Recent events in the economy have forced organizations to reflect on their budgets and overall costs of doing business, instituting changes, and future projects. Seemingly, this would not be a huge problem if organizations would realize that change is necessary and sometimes costly. Maintaining the perception that change is not necessary and that things are good can be a mistake. ${ }^{14}$

Conditions have changed, and groupthink often seen in older organizations has to change. Continuing to keep things the way they are may result in more spending as costs are incurred to maintain older systems (ie, upgrades, breakdowns, data breaches). Budget cuts and tight spending are the reason for some resistance to change as well. ${ }^{11}$ Egos are 
also a contributing factor to change resistance. Staff with inflated sense of self-worth and egotistical views would not allow for change as they would be boastful in adhering to how things were and not how things could be.

Organizations have to weed out managers and staff who have egos that could be detrimental to change in business process systems. Not only will they be ineffective, but they will also be irrational in the process outcome or weaken the organization. ${ }^{14}$ Conducting research is important before making decisions that will impact the organizations and their structure. Do not manipulate the data to fit with an agenda. Proper research reduces the risk of failure versus quick decision-making, which overlooks critical factors. Changing an organization's business processes, implementing changes, and communicating those changes are best done with research and planning. One approach terms the steps of effective research measurement as redefining processes of success: experiment, listen, measure, and learn. ${ }^{11}$

Communication is crucial during every phase of change. Precise planning and effective communication must be thought out, and lines of communication must be kept open throughout the process. This is the time for organizations to be truthful about all the effects of the changes both negative and positive with staff, stakeholders, and patients. ${ }^{21}$ A positive outcome of open communications is the full disclosure of all changes. Data integration requires communication from all parties involved and across multiple servers and databases. Implementation efforts can be impeded if communication is lacking. This includes not using ambiguous terms that will confuse the staff and vendors involved. ${ }^{21}$

The economic recession will force organizations to separate the business processes that they have solidified over time from those that can effectively use a configurable industrialized solution. ${ }^{14}$ HIT success depend upon the workings of many factors and at a cost that some organizations just are not willing to pay. With economic recession in the forefront of HCOs' minds, change processes are approached apprehensively. Hospitals seem willing to pay the cost of buying new equipment, consultant fees, hardware, and software but are hesitant in paying the costs directly related to BPR and the teams needed to implement the systems.

HCOs recognize that aligning physicians who are passionate about and committed to instituting change is important, as they are key players in the succession of upcoming BPR efforts. ${ }^{14}$ The size of HCOs is important as it dictates the amount of staffers needed to complete the transition. It will also create jobs and titles for the various personnel (eg, vendors, vice presidents, senior medical assistants). There is a working relationship that needs to be formed in order to promote a harmonious environment among the change agents (eg, lead physicians and clinicians) and the chief information officer (CIO). Along with overseeing all changes with regard to HIT, the responsibility of those leaders is to nurture relationships that are honest and credible with lower level staff, the community, and vendors. ${ }^{22}$

The underlying principal of lean production is one that has been used in organization setting. It is the application of the theory to reach a desirable outcome behind lean production which appears to be the challenge for organizations. For all intents, it would appear in recent decades that technology is taking over and advancing. BPR in HCOs requires the sharing of information across several servers, which means updating old systems and replacing them with up-to-date systems. It is these costs both in time and finances which are resulting in the resistance to change. ${ }^{14}$ Hiring IT technicians who are qualified to do the job is also challenging. ${ }^{11}$ HCOs are being forced "kicking and screaming" into the technology era, regardless of their attempts not to. It is imperative that the introduction of IT into HCOs' focus is on the enhancement and improvements of systems and not on gadgetry. ${ }^{11}$

\section{Efficiency}

Efficiency is measured as the value of health care services given to patients compared with the cost of operating HCOs. Patient services' effective value is measured by the income generated through the services given. The goal is to give the correct diagnoses on the first visit and not have follow-up visits trying to diagnose the same condition. In order to be efficient, organizations need to eliminate wasteful time and money. This means introducing techniques that are cost efficient and better for the bottom line without passing off the costs to the patients. This could be accomplished by:

\section{Promoting inside the organization}

2. Using IT consultants already on hand to implement BPR

3. Training in house and conferring with other professionals with the same goals ${ }^{23}$

By cutting the cost of hiring outside consultants, HOCs can save money and ensure that the data transferred remains confidential. ${ }^{23}$

This creates a sense of collaboration among the staff and inspires morale throughout the organization. When staffs feel that they have a part in the change and the communication lines are open, the process can move along effectively and efficiently; this reduces stress and conflicts. 
Patients in turn reap benefits from the efforts. Reduced difficulty escalates the benefits organizations develop from investments in technology and organizational change. The consequence is flexible HCOs that are capable of offering high quality of health care services to patients. ${ }^{11}$ One of the main differences of process utilities from more traditional cost-saving resourcefulness is that repeat patients for the same condition, make a measurable variance to the patient when using process utilities. Successful HCOs have learned to benefit from technology in treating patients and giving health care services with high quality care, compared to their competitors. These improvements commonly involve increased automation and better, more efficient organization and processes. ${ }^{11}$

\section{Methods}

The objective of the study was to examine if there was a significant mean score difference in the manner in which health organizations in eastern North Carolina used BPR deployment to support the implementation of HIT. A descriptive study was selected as the most appropriate research method because the study was based upon information elicited from HCOs utilizing a BPR questionnaire completed by knowledgeable persons of the HCO. Each questionnaire was statistically tested between and against health organizations, and all results were presented as aggregate, summary data. Statistical software programs, such as Excel, were used to record and convert information and then analyze the data.

The conceptual framework developed is based on an exploration of the relations between operational use of BPR deployment to support health organizations and adopting HIT for organizational optimization over quality and patient care. Research has indicated that certain functions of HIT can be implemented with organizational optimization and patient-centered care being a distant second. This was shown in a study by BioMed Ltd in 2006, which concluded that adoption of functionalities with organizational optimization (financial benefits) far exceeds adoption of those with safety and quality benefits. ${ }^{24}$

In general, previous work has concluded that adoption of HIT with organization optimization (financial benefits) far exceeds adoption of those with operational efficiency. The research question is: Is BPR being used in HIT implementation? This research was centered on two testable hypotheses motivated by BPR to support the implementation of HIT:

$\mathrm{H}_{1}$ : It is hypothesized that there will be a significant statisti-

cal mean score difference by type of health organization in eastern North Carolina in the deployment of BPR for HIT implementation.

$\mathrm{H}_{0}$ : It is hypothesized that there will not be a significant statistical mean score difference by type of health organization in eastern North Carolina in the deployment of BPR for HIT implementation.

Researchers have used the Theory of Reasoned Action and the Theory of Planned Behavior to examine and understand behaviors connected to adoption of IT. ${ }^{14}$ However, the researchers reasoned that the focal point for HCOs was pressures to reduce health care cost and change management. The Simon's behavioral theory of bounded rationality was the starting point for this research analysis, which implies that profit increase or optimization is the goal of organizations. ${ }^{25}$ Simon believed that human rationality is bounded by external, social, and internal cognitive restrictions. ${ }^{25}$

This would account for choosing functions of HIT which are implemented based on cost and rate of return. However, this does not fully explain implementation and adoption alone. The model for the alignment of a technological analytic approach begins with a technology being implemented into an organization and traces its influences on technology users across social analysis, to demonstrate how social structure change does or does not occur in organizations. ${ }^{26}$ For the premise of this study, diffusion will be recognized as BPR and the innovation will be HIT that will be communicated to HCOs. ${ }^{27}$ The first element that determines diffusion is the innovation. DOI theory outlines five attributes important in assessing the diffusion potential of an innovation. These consist of the following:

1. Relative advantage: Is it improved over what it substitutes?

2. Compatibility: Is it constant with standards and requirements of users?

3. Complexity: Is it difficult to comprehend and utilize?

4. Trial potential and volume: You conduct an experiment with it?

5. Observability: Is outcome measurable or seen by others? ${ }^{28}$

The next element that is imperative in diffusion is communication; sharing ideas has the potential to be carried out through various modes of communicative exchanges. Time is the third element of the diffusion process: at the singular level, HCOs can be categorized as innovators, early adopters, early majority adopters, late majority adopters, or laggards. At the diffusion process level, time is a measure of HIT adoption through HCOs. The fourth element of diffusion is the HCOs through which the innovation diffuses. ${ }^{11}$ There have been numerous studies on the benefits of HIT, 
and given these advantages, what is it about HIT that has hindered its diffusion?

The quantitative research design is descriptive research to determine the current factors of BPR for the implementation of HIT. Descriptive research was used to attain data relating to the prominence of the phenomena to describe "what exists" with respect to variables or conditions related to BPR deployment in HIT. ${ }^{29}$ The purpose of this survey study was to test the theory of DOI that compares the HCOs type to BPR deployment, controlling for the type of health organizations in one of these categories:

1. Integrated delivery networks

2. Community stand-alone hospitals

3. $\mathrm{SNFs} / \mathrm{LTC}$

4. Rehabilitation centers/clinics

5. Physician practices

6. Home health agencies

7. Assisted living facilities in eastern North Carolina

The dependent variable BPR was generally defined as a tool supporting the implementation of HIT, and the control and intervening variables, health organizations and BPR deployment, were statistically controlled in the study.

The survey instruments requested information from each of the HCOs participating, and the validity and reliability of the survey instrument emanated from research, testing, and expertise of Kettinger et al in the field of BPR. Each of the eleven contingency factors is rooted in the various components of business process change. ${ }^{30}$ Dr. William J Kettinger gave permission to use the adaptive version. For this reason, a pilot test was not done on the survey instrument. This instrument is appropriate for assessing BPR techniques and usage. The Argosy University Internal Review Board (IRB) approved this study.

Each questionnaire was statistically tested between and against health organizations, and all results were presented as aggregate, summary data. Statistical software programs, such as Excel, were used to record and convert information and then analyze the data in an effort to reveal factors of BPR deployment for the implementation of HIT. To measure the factors of BPR deployment, a scale was constructed by counting the number of items from a list of 12 BPR factors for each health organization reporting. The scale constructed takes on values ranging from 1 to $5 .^{31}$

The data were used to describe if BPR factors were used when implementing HIT. Questionnaire data is presented through a grading scale. The $F$-test was used at a 0.5 level of significance. The $F$-test is used to calculate if two population variances are the same, by comparing the ratio of the two variances. If the variances are equal, the ratio of variance will be $1 .{ }^{32}$ Many of the chi-square properties transfer over to the $F$-distribution.

1. The $F$-values are all nonnegative.

2. The distribution is nonsymmetric.

3. The mean is approximately 1 .

4. There are two independent degrees of freedom, one for the numerator and one for the denominator.

5. There are many different $F$-distributions, one for each pair of degrees of freedom. ${ }^{32}$

Within several predefined groups, the $F$-test in a oneway analysis of variance was used to assess whether the predictable values of a quantitative variable fluctuate from each other. The test statistic in an $F$-test is the ratio of two scaled sums of squares reflecting different sources of variability. These sums of squares are constructed so that the statistic tends to be greater when the null hypothesis is not true. In order for the statistic to follow the $F$-distribution under the null hypothesis, the sums of squares should be statistically independent, and each should follow a scaled chi-squared distribution. The sources of confounding variables did not pose a serious threat to the internal validity of the study because the researcher was able to measure and account for the effects of extraneous variables. ${ }^{33}$ One goal of this study was to develop information that could be applied directly to other research settings. Therefore, external validity (eg, the degree to which a study's findings can be extended beyond the limited research setting and sample from which they were obtained) was an important aspect of this study.

\section{Results}

A total of $63 \mathrm{HCOs}$ decided to participate in the study, representing $25.2 \%$ participation. The 187 HCOs who did not participate in the study represented $74.8 \%$ nonparticipation. Figure 1 shows the rate of return.

Based on the $74.8 \%$ nonparticipation at the time of the research, the HIT was not being properly implemented or the use of BPR was not fully understood. The researcher has to note that the research started in 2010 and finished in 2011 at the prime time that HIT was being implemented in North Carolina. In early 2010, many HCOs had not implemented HIT. Many of the HCOs that were contacted but did not respond were located in rural areas within North Carolina. However, the research is still valuable in this day and time. The large disparity in participation directly relates to lack of 
understanding and the necessity for the BPR deployment in the implementation of HIT. Additionally, in a more recent follow-up, (SNFs or) LTC and rehabilitation centers still have not implemented HIT. This is due in part to following under different guidelines of the Patient Protection and Care Act (PPACA) than doctors' offices and hospitals.

Even though many HCOs have been attempting to comply with the PPACA, the number one concern is where the money will come from to fund this initiative. The major difference in the HCOs is the amount of revenue brought in by the health organization. This directly relates to the budget they have for the implementation of HIT. Larger HCOs have budgets allotted for the implementation and upgrading of HIT, whereas smaller HCOs in rural areas do not have budgets for HIT implementation and upgrades. The larger HCOs such as hospitals have personnel and information systems offices to assist with the transition to HIT.

\section{Implementation of HIT}

This question related as to whether HCOs had implemented HIT. The participants $(65.1 \%)$ who responded had implemented HIT. The remaining (34.9\%) HCOs revealed that they had not implemented any form of HIT. Physician practices (20.6\%) that were categorized as small office or small had the highest number for not implementing HIT. This question was pertinent to determine a baseline for the implementation of HIT. When the research started, there was an assumption that all HCOs had implemented some type of HIT. Another difference is the amount of funding these HCOs were able to raise. Some larger HCOs had personnel or staff that specialize in grant writing and fund raising, whereas the smaller HCOs had minimum staff to take care of their patients and daily routines.

There is also a difference in classification, whether the health organization is classified as nonprofit or profit. This again relates to the amount of capital they have the ability to raise and the different rules and regulations they must adhere to. HIT is so much more than a systematic sharing database. It is more than just a plan; it is a commitment to change. It requires a clear and concise plan of action, time, patience, dedication, training, implementation, communication, and teamwork. Table 1 shows overall responses to implementation of HIT.

HCOs and plans have reached a defining moment in the industry, and their success depends on how they choose to proceed. Consciously implementing new tools and approaches, such as analytics and EHR integration, has the ability to craft balance within plans and inform decision making and the use of resources as they seek to improve the health and well-being of their enrollees. ${ }^{34}$ Opportunities arise because powerful analytics serve as an informatics catalyst that can convert risk scores from a vulnerability to strength, drawing from multiple data sources such as EHRs. ${ }^{34}$

HIT sabotage rates reached over $30 \%$ in hospitals according to Vanderbilt University. ${ }^{35}$ To prevent sabotages in HIT implementation, HCOs need to hire specialists and BPR consultants. Additionally, extensive training in security and ethics is required, due to the amount of data shared in these types of systems, as security breaches are at high risk. Potential hackers could have access to private health information as well as personal information about the patients. Communication will play its most important role during this time. Leaders need to listen to the staff and vendors with concerns or grievances. Leaders in private practice as well as larger networks need to understand that the process of change can be tedious and benefits of the process may not be readily seen. This is even truer for smaller practices that are not as technologically advanced as larger hospitals. ${ }^{35}$ Other concerns may need to be addressed in the smaller private practices. For example, there may be concerns over: hiring IT specialist and vendors, maintaining the cost and up keep of the hardware and software for the new system, what effect would the decision have on the patients, will prices have to change in order to accommodate the new system.

\section{BPR used}

This question relates to the HCOs using BPR to implement HIT. Of the participants who responded (55.6\%), 63 responded with a "do not know" to the use of BPR used to implement HIT. Only 9.5\% responded with a "yes" answer. The remaining $34.9 \%$ represented the participants who had not implemented HIT. Physician practices (25.4\%) that were categorized as small office or small had the highest number of "do not know" responses. The answer to this question was skewed; this would allow the acceptance of the hypothesis that there is a significant statistical mean score difference by type of HCOs in eastern North Carolina in the deployment of BPR for HIT implementation. Table 2 shows the responses to the use of BPR in implementing HIT.

Benchmarking can assist HCOs by recurrent and cooperative self-control of evaluating and linking the outcomes of vital work processes with those of the outstanding HCOs in valuing health organization performance. ${ }^{36}$ Normally, two types of benchmarking are used to gauge patient safety and quality performance. Internal benchmarking is used to recognize best practices within HCOs, to parallel preeminent practices, and to compare existing practices through extended 
periods. ${ }^{36}$ Competitive or external benchmarking embroils utilizing proportional records among HCOs to evaluate performance and recognize improvements that have demonstrated effectiveness. ${ }^{36}$

Over the years, the request for performance has grown into a foremost concern for the health care system. ${ }^{37}$ There are three factors of greatest concern: the imperiousness to govern health care expenses, the requisite to organize control of risk and quality of care, and the need to gratify consumer experiences with HCOs. ${ }^{37}$ These burdens impelled expansion of many HCOs to gauge, develop, and compare performance. ${ }^{37}$ For example, the Agency for Healthcare Research and Quality, the National Quality Forum, the Joint Commission, and several domestic organizations compare measures that are usable and dependable procedures of quality and patient safety which will advance health care.$^{36}$ These measures are usually established by a valuation of the strength in peerreviewed literature, evaluating the usability and dependability procedures of the measures, and the evidence showing the most efficient and effective use of the measure and testing the measure. ${ }^{36}$

Business models and strategies are likely to be critically damaged if new technological changes and results are neglected. IT and organizational learning are both critical to attaining and sustaining competitive advantage. ${ }^{11} \mathrm{~A}$ modern-day study showed that IT spending in the health care industry is at this time $3.9 \%$ of revenues. This is significantly lower than the IT spending in other industries. This means that the health care industry has higher cost than other industries. For instance, the typical expenditure for processing an automated purchase order is under $\$ 30$ in hospitals. In comparison, manual orders could cost over $\$ 70$ per purchase order. ${ }^{38}$

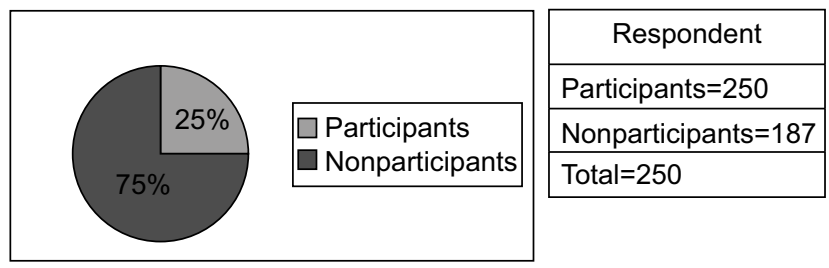

Figure I Overall return rate $(\mathrm{N}=250)$.

Table I Responses to the question on health information technology implementation

\begin{tabular}{lllll}
\hline Valid & Frequency & $\%$ & Valid \% & Cumulative \% \\
\hline Yes & 41 & 65.1 & 65.1 & 65.1 \\
No & 22 & 34.9 & 34.9 & 100 \\
Total & 63 & 100 & 100 & \\
\hline
\end{tabular}

\section{Future research}

The Medical Group Management Association survey examined the use of IT, composed of EHRs, among health organizations with three or more physicians. The last survey was completed in 2005, and contained data on over 3,000 HCOs which can be used to produce approximations of adoption among organizations. There were failings in the database preventing the results of the surveys to be properly analyzed..$^{39}$ There are other surveys that address the use of HIT: the National Ambulatory Medical Care Survey, MGMA, Assessing Adoption of Health Information Technology project, and the National Hospital Ambulatory Medical Care Survey (NHAMCS). However, the NHAMCS only measured EHR adoption in outpatient hospital departments. There needs to be more research using these survey instruments, conducted at closer intervals.

Research into National Health Information Technology Systems (NHITS) coupled with a standardized EHR system would lay the foundation for future research and investigation in showing the opportunities and strengths and investment in scholarship and research in this area. NHITS need to be initiated, allowing EHR data exchange through a health information exchange for all health organizations to operate on a National Health Information Network. This would cut costs and stop the problems of different systems being able to communicate with each other and allow HIT interoperability. Nationally recognized standards would be governed by a health information organization.

Open, equitable, multi-stakeholder-combined authority and managerial processes are required at all levels through Regional Health Information Organization to identify HIT urgencies and decide the path of implementing HIT. ${ }^{40}$ The inclusion of doctor nursing practice allows for buy-in from medical practices that deal with patients each day and are a definite resource to the campaign. ${ }^{41}$ This would allow for sustained medication, health care, and prevention, ultimately giving a voice back to the society in health care and not relying on ability to pay and the old adage of the haves having the better ability to receive the best medical care available.

Table 2 Responses to the question on the use of business process reengineering in implementing health information technology

\begin{tabular}{lllll}
\hline Valid & Frequency & $\%$ & Valid \% & Cumulative \% \\
\hline No response & 22 & 34.9 & 34.9 & 34.9 \\
Yes & 6 & 9.5 & 9.5 & 44.4 \\
Do not know & 35 & 55.6 & 55.6 & 100 \\
Total & 63 & 100 & 100 & \\
\hline
\end{tabular}




\section{Discussion}

Studies have shown underinvestment of HIT as a leading contributor to operational inefficiencies. ${ }^{11}$ Implementation, use, and support of HIT is dependent upon BPR. BPR has the potential to automate information by incorporating IT architecture. ${ }^{17}$ This is one of the many selling points for the BPR process. Amenities offered by BPR efforts can be streamlined and operable in private practice as well as network hospitals. ${ }^{11}$ When examining the positives, HCOs have to view the risks associated realistically. These risks could include wasted time and money, communication breakdowns, unsatisfactory results, data breaches, and other unknown risks. Having a mockup of how the process should work, a contingency plan, and a termination date in advance can help eliminate risky actions. This can be deemed as a trial-and-error phase. This is also the time for senior executives, shareholders, and department heads to determine the feasibility of the BPR process being successful.

Keeping key players apprised of the changes at every stage is important. Securing finances and support is equally important. ${ }^{11}$ Business models, relations, and strategies are likely to be critically damaged if new technological changes and results are neglected and kept under wraps. IT and organizational learning are both critical to attaining and sustaining competitive advantage. ${ }^{11}$ Numerous articles addressing HIT, such as "Assessing the level of health care information technology adoption in the United States: a snapshot", 24 "A diffusion of innovations model of physician order entry", ${ }^{16}$ and "Characterizing the health information technology workforce: analysis from the HIMSS Analytics ${ }^{\mathrm{TM}}$ database" ${ }^{42}$ have developed the foundation for the use of quantitative analysis and the use of surveys for this study.

BioMed Ltd segmented HIT into seven major stakeholder health organization categories that were used in this study. ${ }^{24}$ The seven targeted HCOs were listed as follows:

1. Integrated delivery networks

2. Community stand-alone hospitals

3. Skilled nursing facilities (SNFs)/long-term care (LTC)

4. Rehabilitation centers/clinics

5. Physician practices

6. Home health agencies

7. Assisted living facilities

The survey was conducted with one of the following stakeholders of the health organizations: administration officer, chief financial officer, CIO, chief medical officer, office manager/medical records, IT supervisor, or physician. Human error, forgetful minds, and biases are factors that could come into play when one thinks of the information that has to be remembered and sorted out. By implementing HIT through BPR, HCOs can eliminate human recall. HIT would allow for the sharing, gathering, receiving, and transcribing of information from multiple databases in HCOs. ${ }^{43}$ Many of the smaller HCOs do not have the personnel or budget to assist with the transition to HIT. It must be noted that the number of employees is another difference in the control group. Some HCOs have as little as ten employees, whereas the larger health organizations may have over 500 employees.

\section{Conclusion}

When new HIT systems were added, they were placed where the health organization could best accommodate the systems at that time. By using that approach, accessibility to technology and data was not the problem; the failure or reluctance to finance HIT was the problem. Inadequate financing of HIT results in archaic systems being used passed their shelf-life. This crushes the ability to obtain perilous information like drug interaction. By placing HIT tools such as EHR or CPOE in the hands of health care providers, the tools have the potential to advance patient outcomes and decrease medical mistakes ${ }^{43}$ Many health organizations are still using legacy systems. These legacy systems need the most automation. Native terminal emulation assistance permits health organizations to automate tasks, removing the need for third-party terminal emulation software and tedious "screen-scraping" operations.

Terminal emulation can assist health organizations by decreasing costs and time in automating and managing legacy systems. ${ }^{43}$ This would also start a BPR process in the implementation of HIT which all HCOs would have to adhere to and stop operation inefficiencies. This will include the ability of individual documentation of health records that can be used throughout all HCOs. A model could be the Veterans Health Administration (VHA) because veterans can inquire about medical care at numerous VHA locations throughout the world, using an Internet-based view that offers unified access to medical records.

\section{Author information}

Dr. T. Ray Ruffin has retired from the US navy and currently teaches face-to-face classes during the day, evening, and online as fulltime and adjunct faculty. He is affiliated to colleges and universities including University of Phoenix School of Advanced Studies (SAS), Colorado Technical University, University of Mount Olive, and Wake Technical 
Community College. Affiliated colleges and universities include: University of Phoenix School of Advanced Studies (SAS), Colorado Technical University, and North Carolina Wesleyan College. Affiliate in Charlotte, North Carolina for the University of Phoenix Research Center for Workplace Diversity. Past member and officer of North Carolina Community College Faculty Association (NCCCFA) as Vice President of Communications and North Carolina Computer Instruction Association (NCCIA), serving on the Leadership Team. Dr Ruffin has over 20 years of experience in management (including financial management) and IT experience.

Dr Ruffin completed his postdoctorate degree in healthcare management and leadership in Colorado Technical University. His research interest includes technology and leadership on all levels with a specialty for HIT. Additionally, he is a reviewer for IGI Global and Dove Medical Press Journal Reviewer for Advanced Health Care Technologies, Journal of Healthcare Leadership, Patient Preference and Adherence, and Patient Related Outcome Measures, and is an Editorial Advisory Board member for the Journal of Emerging Trends in Healthcare Administration with Wyvern Publishing Group. Dr Ruffin has published articles that appear in Encyclopedia of Information Science and Technology, Third Edition (pp 3355-3365), Global Handbook of Research on Advancing Health Education through Technology (pp 259-285), and Handbook of Research on Effective Communication, Leadership, and Conflict Resolution (pp 42-62).

\section{Disclosure}

The author reports no conflicts of interest in this work.

\section{References}

1. O'Neill T. Are electronic medical records worth the costs of implementation? 2015. Available from: https://www.americanactionforum. $\mathrm{org} /$ research/are-electronic-medical-records-worth-the-costs-of-implementation. Accessed June 17, 2016.

2. Lohr S. The healing power of your own medical records. 2015. Available from: http://www.nytimes.com/2015/04/01/technology/the-healingpower-of-your-own-medical-data.html. Accessed June 17, 2016.

3. Office of the National Coordinator for Health Information Technology. Patient identification and matching final report. 2014. Available from: https://www.healthit.gov/sites/default/files/patient_identification_matching_final_report.pdf. Accessed June 25, 2016.

4. Khanna R, Yen T. Computerized physician orders entry: promise, perils, and experience. Neurohospitalist. 2014;4(1):26-33.

5. Ruffin TR. Health information technology and business process reengineering. In: Khosrow-Pour M, editor. Encyclopedia of Information Science and Technology. 3rd ed. Hershey, PA: Medical Information Science Reference; 2015:3355-3365.

6. Ginsburg PB, Pawlson LG. Seeking lower prices where providers are consolidated: an examination of market and policy strategies. Health Aff (Millwood). 2014;35(6):1067-1075.

7. Allen M. How many die from medical mistakes in the US hospitals? Patient safety exploring quality of care in the U.S.: journalism. 2013. Available from: https://www.propublica.org/article/how-many-diefrom-medical-mistakes-in-us-hospitals. Accessed June 18, 2016.
8. Friedman E. The paper chase: why are some providers reluctant to embrace health information technology? 2013. Available from: http://www.hhnmag. com/articles/6406-the-paper-chase-why-are-some-providers-reluctant-toembrace-health-information-technology. Accessed June 19, 2016.

9. Beeler P, Bates D, Hug B. Clinical decision support systems. 2014. Available from: https://www.ncbi.nlm.nih.gov/pubmed/25668157. Accessed June 18, 2016.

10. UBS. Extreme automation and connectivity: the global, regional, and investment implications of the Fourth Industrial Revolution. UBS White Paper for the World Economic Forum Annual Meeting 2016. 2016. Available from: https://www.ubs.com/microsites/makerbayelectric-vehicle-project/en/ubs-and-innovations/the-fourth-industrialrevolution-form.html. Accessed June 19, 2016.

11. Cognizant. Strategic cost optimization: driving business innovation while reducing IT costs. 2014. Available from: https://www.cognizant. com/insightswhitepapers/Strategic-Cost-Optimization-Driving-Business-Innovation-While-Reducing-IT-Costs.pdf. Accessed June 19, 2016.

12. Barley SR, Tolbert PS. Institutionalization and structuration: studying the links between action and institution. Organ Stud. 1997;18(1):93-117.

13. Scott WR. Institutions and Organizations. 2nd ed. London: Sage Publications; 2001.

14. Innocentive. 8 differences between traditional and collaborative leaders. 2013. Available from: http://blog.innocentive.com/2013/11/21/8differences-between-traditional-and-collaborative-leaders/. Accessed June 19, 2016

15. Feyereisen SL. Why some change and others do not: understanding the effects of competition in overlapping professional jurisdictions on states, healthcare markets and training programs. 2016. Available from: https://arizona.openrepository.com/arizona/bitstream/10150/578634/1/ azu_etd_14171_sip1_m.pdf. Accessed June 20, 2016.

16. Ash J, Lyman JA, Carpenter JD, Fournier L. A diffusion of innovations model of physician order entry. 2016. Available from: https://www. researchgate.net/publication/11535435_A_Diffusion_of_Innovations_Model_of_Physician_Order_Entry. Accessed June 20, 2016.

17. Projacs Academy. Business process re-engineering BPR. 2015. Available from: http://www.projacs.com/print/course.pdf?course=7036. Accessed June 16, 2016.

18. Burns JR, Jung DG, Hoffman JJ. Capturing and comprehending the behavioral/dynamical interactions within an ERP implementation. J Organ End User Comput. 2009;21(1):67-89.

19. Ruffin TR. Health information technology and change. In: Wang V, editor. Handbook of Research on Advancing Health Education Through Technology. Hershey, PA: Medical Information Science Reference; 2015:259-285.

20. H\&HN. Baldrige award winner uses holistic approach. 2016. Available from: http://www.hhnmag.com/articles/6866-baldrige-awardwinner-uses-holistic-approach. Accessed June 16, 2016.

21. Kidder R. Ethical decision making and behavior. Available from: http:// uk.sagepub.com/sites/default/files/upm-binaries/39590_Chapter7.pdf. Accessed June 15, 2016.

22. Daly J, Jackson D, Mannix J, Davidson PM, Hutchinson M. The importance of clinical leadership in the hospital setting. 2014. Available from: https://www.dovepress.com/the-importance-of-clinical-leadershipin-the-hospital-setting-peer-reviewed-fulltext-article-JHL. Accessed June 18, 2016.

23. Building the business case analysis. What is the budget? Budget, budgeting process, and variance explained. 2016. Available from: https:// www.business-case-analysis.com/budget.html. Accessed June 20, 2016.

24. Poon EG, Jha AK, Christino M, et al. Assessing the level of healthcare information technology adoption in the United States: a snapshot. $B M C$ Med Inform Decis Mak. 2006;6:1.

25. Wray R, Chong R, Phillips J, Rogers S, Bill LW. A survey of cognitive and agent architectures. 1994.

26. Barley SR. The alignment of technology and structure through roles and networks. Adm Sci Q. 1990;35(1):61-103.

27. Rogers. Diffusion of innovation theory. 1971. Available from: http:// www.ou.edu/deptcomm/dodjcc/groups/99A2/theories.htm. Accessed January 2, 2016. 
28. Bauer TN, Erdogan B. The Oxford Handbook of Leader-Member Exchange. Oxford Library of Psychology. England, UK: Oxford University Press; 2015.

29. Judeh M. What do we mean by Descriptive Research? 2014. Available from: https://www.researchgate.net/post/What_do_we_mean_by_ Descriptive_Research. Accessed June 5, 2016.

30. Kettinger W, Teng JTC, Guha S. Business process change: a study of methodologies, techniques, and tools. MIS Q. 1997;21(1):55-98.

31. Morse EV, Gordon G, Moch M. Hospital costs and quality of care: an organizational perspective. Milbank Mem Fund Q Health Soc. 1974; 52(3):315-346.

32. Jones J. Richland Community College. 2009. Available from: http:// people.richland.edu/james/. Accessed January 5, 2016.

33. Bordens KS, Abbott BB. Research Design and Methods: A Process Approach. 6th ed. New York, NY: McGraw-Hill Companies; 2005.

34. Khodambashi S. Business process re-engineering application in healthcare in a relation to health information systems. Procedia Technol. 2013;9:949-957.

35. Carrie A. Changing healthcare landscape demands transformational leaders. 2015. Available from: http://www.beckershospitalreview.com/ hospital-management-administration/changing-healthcare-landscapedemands-transformational-leaders.html. Accessed June 17, 2016.

36. Hughes RG. Chapter 44: Tools and strategies for quality improvement and patient safety. In: Hughes RG, editor. Patient Safety and Quality: An Evidence-Based Handbookfor Nurses. Rockville, MD: Agency for Healthcare Research and Quality; 2008.
37. Ettorchi-Tardy A, Levif M, Michel P. Benchmarking: a method for continuous quality improvement in health. Healthc Policy. 2012;7(4): e101-e119.

38. Porter ME, Lee TH. The strategy that will fix health care. 2013. Available from: https://hbr.org/2013/10/the-strategy-that-will-fix-health-care. Accessed June 22, 2016.

39. Blumenthal D, DesRoches C, Donelan K, et al. Health Information Technology in the United States: The Information Base for Progress. Washington, DC: Robert Wood Johnson Foundation; 2006.

40. Lathrop B, Hodnicki DR. The affordable care act: primary care and the doctor of nursing practice nurse. Online J Issues Nurs. 2014; 19(2):7.

41. O'Connor JC, Gutelius BJ, Girard KE, Drum Hastings D, Longoria L, Kohn MA. Paying for prevention: a critical opportunity for public health. J Law Med Ethics. 2013;41 Suppl 1:69-72.

42. Hersh W, Wright A. Characterizing the health information technology workforce: analysis from the HIMSS Analytics ${ }^{\mathrm{TM}}$ database. 2016. Available from: https://www.researchgate.net/publication/228481812_ Characterizing_the_Health_Information_Technology_Workforce_ Analysis_from_the_HIMSS_Analytics_Database. Accessed June 21, 2016.

43. Jackson M. Kalispell Regional Healthcare replaces legacy systems with Plexus TG's anesthesia information and medication management solutions. 2016. Available from: http://www.bizjournals.com/ prnewswire/press_releases/2016/05/12/PH97747. Accessed June 19, 2016 .
Advanced Health Care Technologies

\section{Publish your work in this journal}

Advanced Health Care Technologies is an international, peer reviewed, open access journal that provides a unique forum for articles on: point-of-care, health care diagnostics and treatment, bioengineering, biotechnology, biosensing, electronics, clinical/medical science, chemical engineering, materials science, regenerative medicine, micro-/
Submit your manuscript here: https://www.dovepress.com/advanced-health-care-technologies-journal

\section{Dovepress}

nano-technologies, and methods and applications for nanoscience and nanotechnology. The manuscript management system is completely online and includes a very quick and fair peer review system, which is all easy to use. Visit http://www.dovepress.com/testimonials.php to read real quotes from published authors. 